\title{
Prognostic value of estrogen receptor-a and progesterone receptor in curatively resected colorectal cancer: a retrospective analysis with independent validations
}

\author{
Shu-Biao Ye ${ }^{1,2+}$, Yi-Kan Cheng ${ }^{3+}$, Lin Zhang ${ }^{4,5,6+}$, Xue-Ping Wang ${ }^{4,5,6}$, Lei Wang ${ }^{1,2}$ and Ping Lan La $^{1,2^{*}}$
}

\begin{abstract}
Background: Prognostic assessment is crucial for optimal treatment. The aim of our study was to investigate the potential impact of estrogen receptor-a (ER-a) and progesterone receptor (PR) on the prognosis of colorectal cancer (CRC) patients who received curative resection.
\end{abstract}

Methods: Retrospective evaluation of two independent cohorts of CRC patients maintained prospectively in 20092010 (training set) ( $n=148)$ and 2007-2009 (internal validation set) $(n=485)$. Furthermore, we used an external independent CRC cohort from The Cancer Genome Atlas (TCGA) $(n=511)$ for further validation. ER- $a$ and PR expression as well as other potential prognostic factors were retrospectively evaluated in training set with respect to overall survival (OS), local relapse free survival (LRFS) and distant metastasis free survival (DMFS). The prognostic factors found in training set will be validated in two validation cohorts.

Results: On univariate analysis for the training set, OS, LRFS and DMFS were not associated with PR expression. While patients with ER-aexpression were found to have poor prognosis. In addition, multivariate analysis showed that ER-aexpression maintained significance with respect to OS (HR, 5.06; $p=0.002)$, LRFS (HR, 8.81; $p=0.002)$ and DMFS (HR, 8.07; $p=0.004)$. Similarly, ER-a expression showed prognostic significance with respect to OS with hazard ratios (HRs) of 1.572 (95\% Cl: 1.001-2.467, $p=0.049)$ and 1.624 (95\% Cl: $1.047-2.520, p=0.031)$ for the internal and external validation cohort, respectively.

Conclusion: ER-a expression was a biomarker of poor prognosis and it might inform treatment decision for high risk CRC patients. However, PR expression was not associated with survival outcomes.

Keywords: Colorectal cancer, Curative resection, Prognosis, Estrogen receptor-a, Progesterone receptor

\section{Background}

Colorectal cancer (CRC) is the third most common cancer and ranks the third in the causes of cancer mortality in the world [1]. Owing to the change of lifestyle, the incidence and mortality of CRC are rising rapidly in developing countries [1]. The survival outcome of CRC is not promising mainly due to local recurrence and distant metastasis [2]. Tumor markers are potentially useful in

\footnotetext{
* Correspondence: lanping@mail.sysu.edu.cn

†'Shu-Biao Ye, Yi-Kan Cheng and Lin Zhang contributed equally to this work. 'Department of Colorectal Surgery, The Sixth Affiliated Hospital, Sun Yat-sen University, Guangzhou, Guangdong, People's Republic of China Full list of author information is available at the end of the article
}

prediction of prognosis and formation of treatment strategy [3]. The TNM staging system provides a useful benchmark for aiding diagnosis, determining prognosis and monitoring treatment. However, patients with same stage and similar treatment regimen may have different clinical outcomes. Considering these, it is crucial to investigate new prognostic biomarkers to reflect the biological heterogeneity of cancer and then to identify high risk CRC patients.

Recent investigations have suggested that the tumor cell expression of hormone receptors may have an impact on the prognosis of patients with CRC [4]. A study from Germany indicated that lack of estrogen receptor

(c) The Author(s). 2019 Open Access This article is distributed under the terms of the Creative Commons Attribution 4.0 International License (http://creativecommons.org/licenses/by/4.0/), which permits unrestricted use, distribution, and reproduction in any medium, provided you give appropriate credit to the original author(s) and the source, provide a link to the Creative Commons license, and indicate if changes were made. The Creative Commons Public Domain Dedication waiver (http://creativecommons.org/publicdomain/zero/1.0/) applies to the data made available in this article, unless otherwise stated. 
(ER)- $\beta$ was independently associated with poor survival [5]. Although ER- $\alpha$ was reported to be implicated in the development and progression of colorectal cancers according to Caiazza et al. [6] and Nussler et al. [7], the prognostic value of ER- $\alpha$ in CRC needs to be investigated. Furthermore, a study from the United States suggested that the expression of PR by the tumor cells may be associated with a shorter patient survival [8].

Epidemiologic investigations indicated that men are more likely to develop CRC at all stage than women [9, 10]. In addition, a meta-analysis conducted by Harvard University [11] and a population-based case-control study from German [12] demonstrated that exposure to exogenous hormones has been found to be associated with a reduced risk for CRC in postmenopausal women. Thus, ER and PR may play a role in the genesis and development of CRC; but the prognostic value of ER- $\alpha$ and PR expression in CRC patients remains unclear.

It is increasingly recognized that variations within clinical outcome in cancer patients are affected by not only the oncological characteristics such as stage but also the host factors. Thus, investigating the potential prognostic impact of tumor cell expression of hormone receptors combining with other host clinical characteristics appears important. The aim of this study was therefore to investigate the potential prognostic impact of tumor cell expression of hormone receptors in terms of local relapse-free survival (LRFS), distant metastasis-free survival (DMFS), and overall survival (OS) in patients who received curative resection for non-metastatic CRC and further to validate the prognostic role in two independent CRC datasets.

\section{Methods}

\section{Study design and patients \\ Training set}

Subjects were included from November 2009 until October 2010. Those eligible for.

inclusion were patients who underwent curative resection for non-metastatic CRC at Sun Yat-Sen University Cancer Center. Tumor tissue from 148 patients was available and the prognostic value of ER- $\alpha$ and PR were determined by immunohistochemistry.

\section{Internal validation set}

Internal validation set consisted of patients referred consecutively with a confirmed diagnosis of non-metastatic CRC. This cohort of 485 patients was included at registries from September 2007 October 2009.

For training and internal validation cohorts, patient data regarding: demography, tumor stage, tumor localization and survival were retrieved from patient files and registries.

\section{External validation set}

Findings from the above both cohorts were compared to a publicly available, open-access, dataset of CRC from The Cancer Genome Atlas (TCGA) (https://tcga-data. nci.nih.gov/tcga/) (March 16th, 2017 update). For external validation set, patient data regarding: ER- $\alpha$ expression level, demography, tumor stage, tumor localization and survival were available.

\section{Immunohistochemistry}

The tissue samples from training and internal validation cohorts were obtained from resected specimens. The tissues were fixed in $10 \%$ buffered formalin (PH7.0) and embedded in paraffin. The paraffin-embedded tumor samples were sectioned continuously into $4-\mu \mathrm{m}$-thick sections. Then the sections were dewaxed in xylene and rehydrated in graded alcohols. A negative control was performed by replacing the primary antibody with a normal rabbit IgG antibody. Following antigen retrieval by microwave heating $\left(95^{\circ} \mathrm{C}\right.$ for $\left.20 \mathrm{~min}\right)$, sections were then incubated with primary monoclonal rabbit anti-human PR (Clone 1E2, Ventana Medical Systems. Inc) (for training set only) or ER (Clone SP1, Ventana Medical Systems. Inc) at $4{ }^{\circ} \mathrm{C}$ overnight. After washing, the sections were incubated with a horseradish peroxidaselabeled goat antibody against a mouse/rabbit secondary antibody (Envision; Dako, Glostrup, Denmark) at room

Table 1 Baseline characteristics

\begin{tabular}{|c|c|c|c|}
\hline & Training set & $\begin{array}{l}\text { Internal } \\
\text { validation set }\end{array}$ & $\begin{array}{l}\text { External } \\
\text { validation set }\end{array}$ \\
\hline Number of patients & 148 & 485 & 511 \\
\hline \multicolumn{4}{|l|}{ Patient demographics } \\
\hline Median age (min-max) & $58(16-89)$ & $59(16-86)$ & $68(31-90)$ \\
\hline Male (number, \%) & $91(61.5 \%)$ & $290(59.8 \%)$ & $270(52.8 \%)$ \\
\hline \multicolumn{4}{|l|}{ Localization } \\
\hline Colon & 77 (52.0\%) & $221(45.6 \%)$ & $379(74.2 \%)$ \\
\hline Rectum & $71(48.0 \%)$ & $264(54.4 \%)$ & $132(25.8 \%)$ \\
\hline \multicolumn{4}{|l|}{ Stage } \\
\hline Stage I & $22(14.9 \%)$ & $99(20.4 \%)$ & $106(20.7 \%)$ \\
\hline Stage \| & $64(43.2 \%)$ & 178 (36.7\%) & $224(43.8 \%)$ \\
\hline Stage III & $62(41.9 \%)$ & 208 (42.9\%) & $181(35.4 \%)$ \\
\hline \multicolumn{4}{|l|}{ ER-a expression } \\
\hline High (number, \%) & 19 (12.8\%) & 78 (16.1\%) & 158 (30.9\%) \\
\hline Low (number, \%) & $129(87.2 \%)$ & 407 (83.9\%) & $353(69.1 \%)$ \\
\hline \multicolumn{4}{|l|}{ PR expression } \\
\hline High (number, \%) & $32(21.6 \%)$ & & \\
\hline Low (number, \%) & $116(78.4 \%)$ & & \\
\hline
\end{tabular}

Baseline characteristics of the two cohorts regarding demography (age and gender), tumor features (stage and localization), ER-a expression and PR expression (just in training set)

Abbreviations: $E R-a$ estrogen receptor $-a, P R$ progesterone receptor 


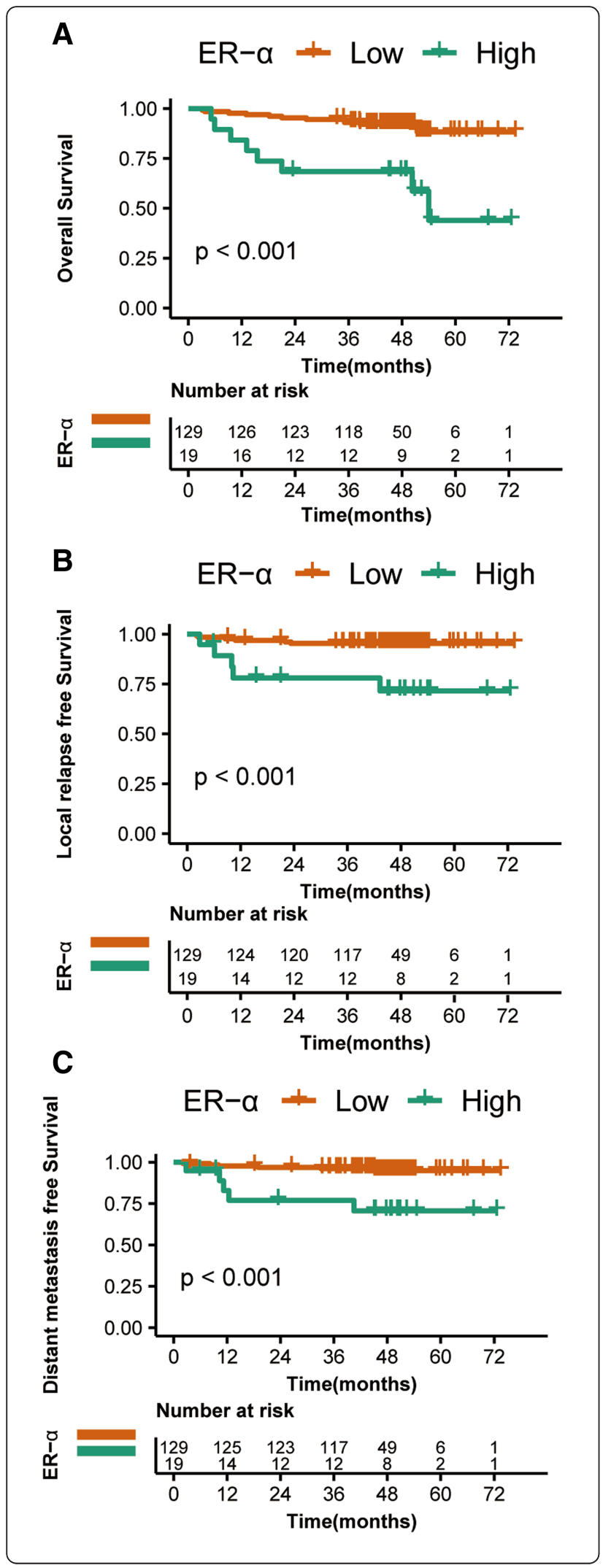

Fig. 1 Kaplan-Meier survival curves for the patients with CRC patients from training cohort in the high ER-a expression group and low expression group. a Overall survival, $\mathbf{b}$ distant metastasis-free survival, c local relapse-free survival

temperature for $30 \mathrm{~min}$. Then the signal was developed with 3, 3'-diaminobenzidine tetrahydrochloride (DAB). Section was counterstained with hematoxylin. The stain was examined by two pathologists independently. The data were obtained by calculating the mean number of positively stained cells in five to ten separate $400 \times$ per high power field(HPF) and evaluated as negative or positive. Two independent observers blinded to the clinicopathological information scored the ER- $\alpha$ and $P R$ expression levels in tumor cells by assessing (a) the proportion of positively stained cells: $(0,<5 \% ; 1,6$ to $25 \%$; , 26 to $50 \% ; 3,51$ to $75 \% ; 4,>75 \%$ ) and (b) the signal intensity: ( 0 , no signal; 1 , weak; 2 , moderate; 3 , strong). The score was the product of $\mathrm{a} \times \mathrm{b}$. Considering that the number of patients with score $>0$ in ER- $\alpha$ and PR expression were 19 (12.8\%) and 32 (21.6\%), we used dichotomic classification (positive/negative). Therefore, the patients were divided into subgroups: a high group $(\mathrm{a} \times \mathrm{b}>0)$ and a low group $(a \times b=0)$. The score $a$ and $b$ were the averages of scores of two independent observers. Immunohistochemical staining was showed in Additional file 1: Figure S1.

\section{Treatment}

For training and internal validation cohorts, the final decisions with regard to treatment strategy and use of chemotherapy or radiotherapy were based on TNM stage, the multidisciplinary team's (MDT) decision and patient choice. All patients were treated with definitive-intent surgery. Most of the patients with stage II-III rectal cancer received radiotherapy. 5-FU based chemotherapy was delivered concurrently with radiation in forms of threedimensional conformal radiotherapy (3D-CRT), intensitymodulated radiotherapy (IMRT) or Volumetric Modulated Arc Therapy (VMAT). Neoadjuvant or adjuvant chemotherapy consisted of oxaliplatin $\left(130 \mathrm{mg} / \mathrm{m}^{2}\right.$, day 1$)$ with capecitabine $\left(1000 \mathrm{mg} / \mathrm{m}^{2}\right.$, bid, days $\left.1-14\right)$ every 3 weeks to a total of 6 months' perioperative therapy or Leucovorin ( $400 \mathrm{mg} / \mathrm{m}^{2}$ or $200 \mathrm{mg} / \mathrm{m}^{2}$, day1), with 5-fluorouracil (5FU) (bolus $400 \mathrm{mg} / \mathrm{m}^{2}$ and then $1200 \mathrm{mg} / \mathrm{m}^{2} /$ day over 46 $48 \mathrm{~h}$ ) every 2 weeks to a total of 6 months' perioperative therapy. Of 148 patients, 12 (8.1\%) patients received neoadjuvant chemotherapy and $86(58.1 \%)$ patients received adjuvant chemotherapy. All patients from external validation cohort (TCGA dataset) underwent surgery.

\section{Follow-up}

Follow-up for training and internal validation cohorts was measured from the first day of treatment until the day of last examination or the day of death. Patients 
were evaluated every 3 months for the first 2 years, and then every 6 months for the next 3 years and finally annually. Relapse local disease was diagnosed pathologically by surgical resection, biopsy or cytology and/or by the detection of radiologically obvious lesions that increased in size over time. Additional tests were ordered when indicated to identify distant failure.

\section{Statistical analysis}

The cut-off values in external validation cohort (TCGA cohort) were obtained using X-tile (Version 3.6.1, Yale University, New Haven, CT). All survival analyses were done with STATA 12 statistical software (Stata Corp LP, College Station, Texas, USA). OS, DMFS and LRFS were all estimated by the Kaplan-Meier method and the survival curves compared using the log-rank tests. The following outcomes of interest (interval to the first defining event) were evaluated: OS, LRFS and DMFS. We calculated OS from commencement of treatment to death or the date of last follow-up visit for surviving patients. The latencies (i.e., time from commencement of treatment) to the first local or remote relapse were calculated for LRFS and DMFS, respectively.

Multivariate analyses using the Cox proportional hazards model were used to estimate the hazard ratios (HR) and test independent significance by backward elimination of insignificant explanatory variables. Covariates included host factors (i.e., sex, age,), and tumor factors (i.e., tumor localization, stage), the criterion for statistical significance was set at $p=0.05$ and $p$ values were based on 2-sided tests.

\section{Results}

\section{Patient characteristics}

The median follow-up duration was 46.8 months (3.1-73.5 months) for training cohort, 64.7 months (0.2-150.1 months) for internal validation cohort and 23.8 months (0.2-105.1 months) for external validation cohort, respectively. The patients' baseline characteristics of three cohorts are presented in Table 1.

\section{Impact of tumor expression of ER- $a$ and PR on survival outcomes in training cohort}

To investigate the effect of tumor expression of ER- $\alpha, P R$ on the outcomes of patients with CRC, the 5-year actuarial OS, DMFS and LRFS rates in training cohort were analyzed. On univariate analysis, low and high ER- $\alpha$ expression demonstrated significant differences in the 5-year OS $(89 \%$ vs. $47 \%, p<0.001$ ), LRFS ( $95 \%$ vs. $71 \%, p<0.001)$ and DMFS (95\% vs. $70 \%, p<0.001$ ) (Fig. 1, Tables 2 and 3 ) rates of CRC patients, while PR were not found to be significantly associated with improved 5-year OS, LRFS and DMFS rates (Additional file 1: Table S1).

In the COX multivariate analysis, the following parameters were included: age ( $<60$ years, $\geq 60$ years), sex, location of tumor, stage (I, II-III) tumor expression of ER- $\alpha$. Stage

Table 2 Overall survival analyses for training and validation cohorts

\begin{tabular}{|c|c|c|c|c|c|c|}
\hline & \multicolumn{2}{|l|}{ Training set } & \multicolumn{2}{|c|}{ Internal validation set } & \multicolumn{2}{|c|}{ External validation set } \\
\hline & $\begin{array}{l}\text { Hazard ratio } \\
(95 \% \mathrm{Cl})\end{array}$ & $P$ value & $\begin{array}{l}\text { Hazard ratio } \\
(95 \% \mathrm{Cl})\end{array}$ & $P$ value & $\begin{array}{l}\text { Hazard ratio } \\
(95 \% \mathrm{Cl})\end{array}$ & $P$ value \\
\hline \multicolumn{7}{|l|}{ Univariate } \\
\hline \multicolumn{7}{|l|}{ ER-a } \\
\hline High vs. low & $5.221(2.073-13.146)$ & $<0.001^{*}$ & $1.596(1.020-2.497)$ & $0.039^{*}$ & $1.774(1.145-2.749)$ & $0.02^{*}$ \\
\hline \multicolumn{7}{|l|}{$P R$} \\
\hline High vs. low & & 0.869 & & & & \\
\hline \multicolumn{7}{|l|}{ Multivariate } \\
\hline \multicolumn{7}{|l|}{ Age } \\
\hline$>60 y$ vs. $\leq 60 y$ & $0.462(0.178-1.196)$ & 0.112 & $1.111(0.762-1.621)$ & 0.584 & $2.029(1.149-3.585)$ & $0.015^{*}$ \\
\hline \multicolumn{7}{|l|}{ Gender } \\
\hline Female vs. male & $1.143(0.427-3.062)$ & 0.790 & $0.890(0.605-1.309)$ & 0.554 & $1.154(0.747-1.781)$ & 0.519 \\
\hline \multicolumn{7}{|l|}{ Stage } \\
\hline Stage II- III vs. I & $2.841(1.230-6.558)$ & $0.014^{*}$ & $1.715(1.287-2.287)$ & $0.000^{*}$ & $2.654(1.153-6.110)$ & $0.022^{*}$ \\
\hline \multicolumn{7}{|l|}{ Localization } \\
\hline Rectum vs. colon & $0.909(0.354-2.333)$ & 0.842 & $1.861(1.271-2.727)$ & $0.001^{*}$ & $1.140(0.667-1.947)$ & 0.632 \\
\hline \multicolumn{7}{|l|}{ ER-a } \\
\hline High vs. low & $5.061(1.833-13.968)$ & $0.002^{*}$ & $1.572(1.001-2.467)$ & $0.049^{*}$ & $1.624(1.047-2.520)$ & $0.031^{*}$ \\
\hline
\end{tabular}

Uni- and multivariate survival analyses for risk of death. Hazard ratios were calculated by the adjusted Cox proportional hazards model Abbreviations: $E R-a$ estrogen receptor $-\mathrm{a}, P R$ progesterone receptor

*statistically significant 
Table 3 Local recurrence-free survival and distant metastasis-free survival analyses for training and internal validation cohorts

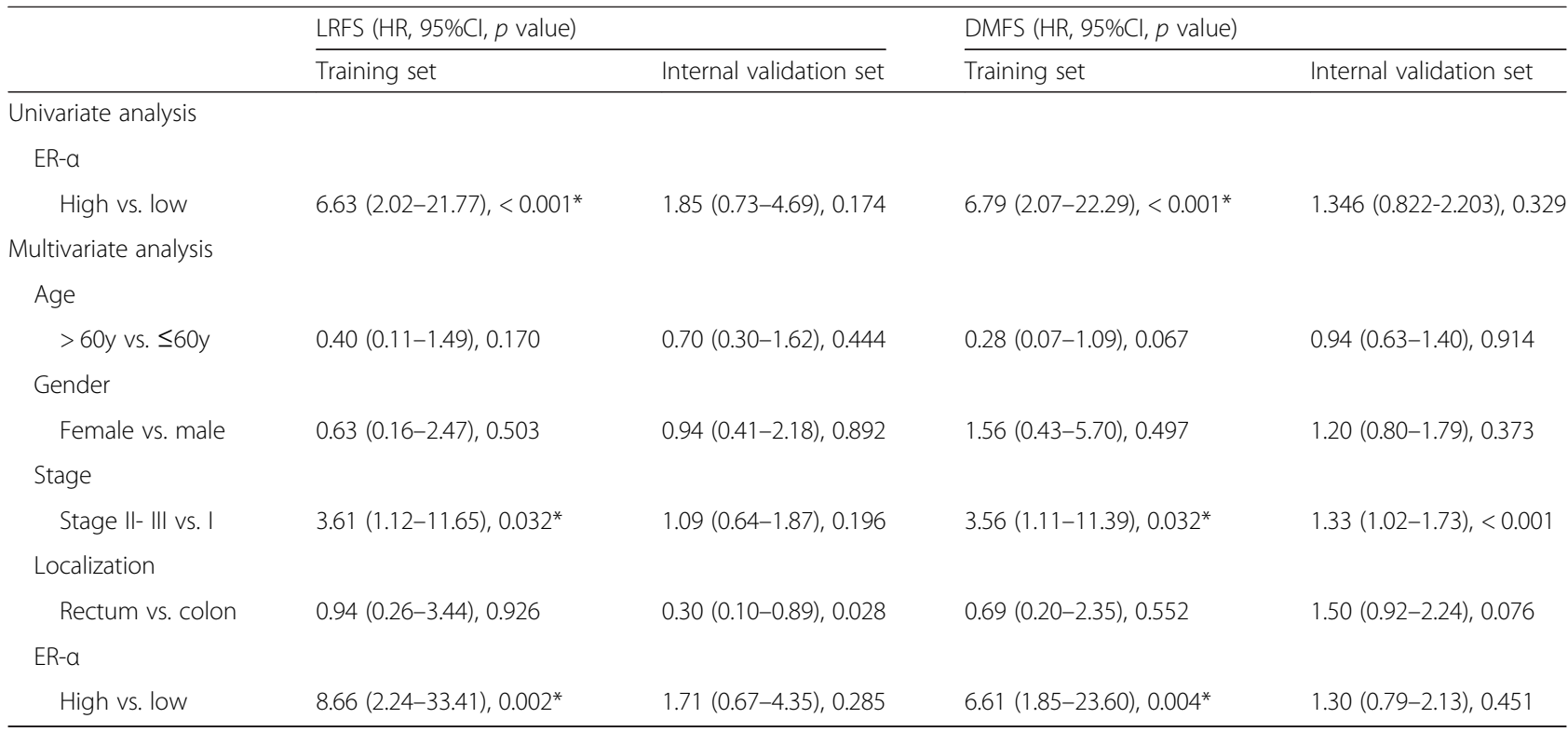

Uni- and multivariate survival analyses. Hazard ratios were calculated by the adjusted Cox proportional hazards model

Abbreviations: $E R-a$ estrogen receptor - $a$

*statistically significant

maintained statistical significance in OS. In addition, ER- $\alpha$ expression was an independent prognostic factor for OS in CRC patients with surgery (HR,5.061; $p=0.002)$ (Table 2), LRFS (HR, 8. 655; $p=0.002)$ and DMFS (HR, 6.610; $p=0.004$ ) (Table 3).

Validation of prognostic value of ER-a expression on survival outcomes in internal and external validation cohorts

To validate the prognostic value of ER- $\alpha$, the 5 -year actuarial OS, DMFS and LRFS rates in internal validation cohort and the 5-year actuarial OS rates in external validation cohort were analyzed. On univariate analysis, tumor expression of ER- $\alpha$ demonstrated significant differences in the 5-year OS rates in internal and external validation cohorts, which are $74 \%$ vs. $61 \%$ with $p=0.039$ and $53 \%$ vs. $38 \%$ with $p=0.02$ (Fig. 2), respectively. Whereas, univariate analyses indicated that ER- $\alpha$ expression had no significant association with DMFS and LRFS in internal validation cohort (Table 3). Since there is no data about local recurrence and distant metastasis in external validation cohort (TCGA dataset), DMFS and LRFS were not validated in this set.
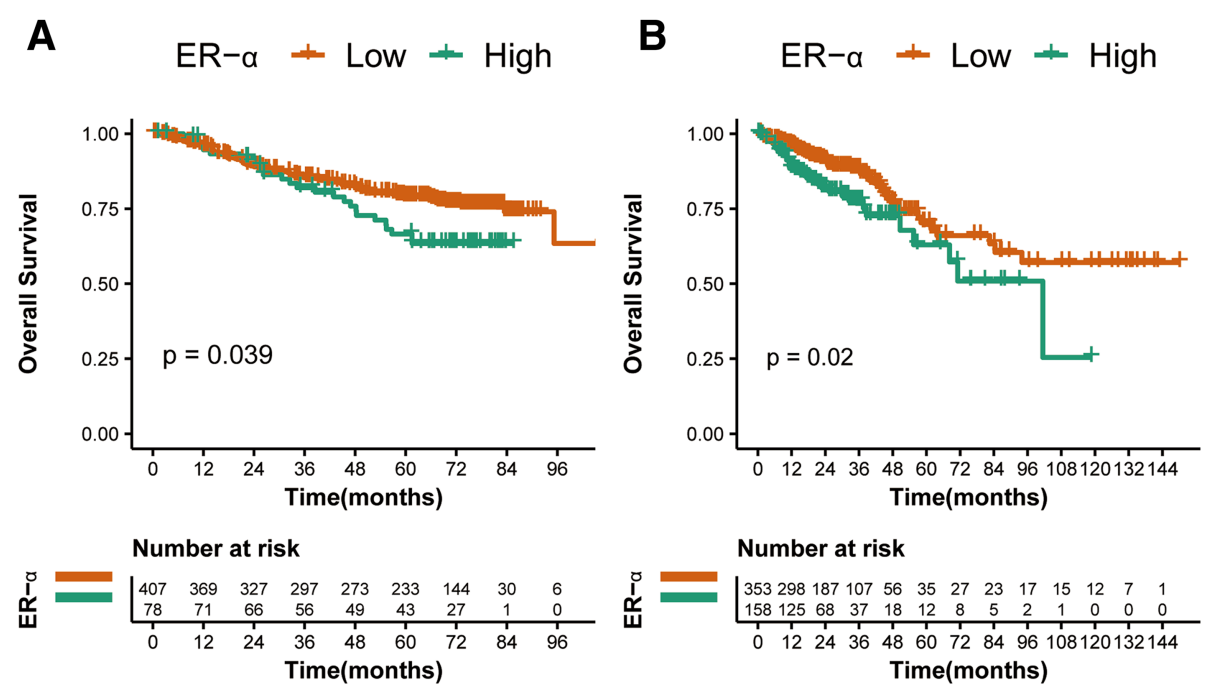

Fig. 2 Kaplan-Meier survival curves of overall survival for the patients with CRC patients. a Internal validation cohort for high ER-a expression group and low expression group, $\mathbf{b}$ External validation cohort for high ER-a expression group and low expression group 
In the COX multivariate analysis, ER- $\alpha$ expression was an independent prognostic factor for OS in both validation cohorts, with $\mathrm{HR}=1.572,95 \% \mathrm{CI}(1.001-2.467)$, $p=0.049$ and $\mathrm{HR}=1.624,95 \% \mathrm{CI}(1.047-2.520), p=$ 0.031 for internal and external validation sets (Table 2).

\section{Discussion}

Prognostic assessment is crucial for optimal treatment. In routine clinical practice, the TNM staging system is the most important prognostic determinant for the treatment strategy in CRC patients. However, patients with the same stage have been reported to have various survival outcomes, which suggests that identifying more potential prognostic markers are necessary. We investigated the prognostic value of tumor cell expression of ER- $\alpha$ and PR in CRC patient. And the results demonstrated that ER- $\alpha$ expression was predictive of survival of CRC patients independent of stage, allowing clinicians to potentially identify high risk patients for more intensive treatment to improve survival outcomes. More importantly, the prognostic value of ER- $\alpha$ expression was confirmed by independent internal and external CRC datasets in our study in spite of differences in expression due to distinct genetic background and analytic methods. However, the results in training cohort did not indicate the clinical validity of PR expression as a prognostic biomarker.

ER- $\alpha$ can be used as prognostic biomarker in many types of cancer and might be implicated to tumor progression of CRC [13]. Therefore, we aim to investigate the potential impact on prognosis in patients with CRC. In gastric cancer, ER- $\alpha$ expression is generally an indicator for a poor prognosis [14] which we anticipated would be the same case in CRC. Our study found that ER- $\alpha$ expression was a negative prognostic factor as it was in lung cancer and hepatocellular carcinoma [15, 16]. These studies implied that ER- $\alpha$ mediated antiapoptotic signal ways might be one of reasons for poor survival [17]. Otherwise, loss of ER- $\beta$ in CRC has been associated with advanced cancer stages and poor prognosis $[5,18,19]$. In addition, decreased ER- $\beta$ expression concurrent with increased ER- $\alpha$ expression have been reported to play a key role on cancer development and advanced stages $[13,20]$. Therefore, the prognostic impact of ER- $\alpha$ and ER- $\beta$ appears to be different in CRC, which occurs as well in other gastrointestinal tumors like gastric cancer [14] and esophageal cancer [21]. Our findings suggested that PR expression was not a prognostic factor in CRC patients. According to Heijmans et al., PR signaling has no role in intestinal tumorigenesis, which indicated that PR expression may contribute little to tumor genesis and development [22].

At present, the standard treatment for locoregionally advanced CRC is surgery with neoadjuvant or adjuvant chemoradiotherapy, and local or distant relapses occurred in almost $50 \%$ of patients. This pattern of failure suggests that certain subgroup of patients do not benefit from present strategies. Thus, the accurate identification of subgroups of patients lead to more individualized therapy. Patients with ER- $\alpha$ expression had poorer survival than those without ER- $\alpha$ expression, and therefore further studies are needed to identify more intensive systemic approaches to improve the treatment outcomes of patients with ER- $\alpha$ expression.

The present study with validation from two independent CRC datasets indicated that ER- $\alpha$ expression was a prognostic factor independent of stage, leading to personalized therapy. When interpreting the results, the retrospective nature of the present study and the heterogeneity of three cohorts should be considered. Hence, we acknowledge that prospective, large-scale, multicenter studies are necessary to confirm our results. In addition, the mechanism behind the prognostic value in CRC is unclear. Further studies on the role of ER- $\alpha$ in CRC are warranted.

\section{Conclusion}

ER- $\alpha$ expression was a marker of poor prognosis and it might inform treatment decision for high risk CRC patients. However, PR expression was not associated with survival outcomes.

\section{Additional file}

Additional file 1: Figure S1. Immunohistochemical staining for estrogen receptor- $a$ (ER-a) and progesterone receptor (PR) in human colorectal cancer. Our data showed high expression of ER-a (A, X 100; B, X 400) and high expression of PR ( $C, X 100 ; D, X$ 400) low expression ( $E, X 100 ; F, X 400$ ) in tumor tissues from patients with CRC. Table S1. Univariate survival analysis of ER- $a$ and PR expression in training cohort. (ZIP $8731 \mathrm{~kb}$ )

\section{Abbreviations}

3D-CRT: Three-dimensional conformal radiotherapy; CRC: Colorectal cancer; DMFS: Distant metastasis-free survival; ER-a: Estrogen receptor-a; HR: Hazard ratios; IMRT: Intensity-modulated radiotherapy; LRFS: Local relapse-free survival; OS: Overall survival; PR: Progesterone receptor; TCGA: The Cancer Genome Atlas; VMAT: Volumetric Modulated Arc Therapy

\section{Acknowledgements}

We thank Yi-na Liu, and Ting-ting Cai for their assistance in data collection.

\section{Authors' contributions}

S-BY, Y-KC and LZ have made substantial contributions to the acquisition, analysis and interpretation of data; and the creation of new software used in the work and have drafted the work or substantively revised it. X-PW have made substantial contributions to the acquisition of the data. PL and LW have made substantial contributions to the conception, design of the work and revised the work. All authors have read and approved the manuscript.

\section{Funding}

This work was supported by the National Natural Science Foundation of China (Grant No. 81703060, 81802441) for the design of the study and the collection of data, Natural Science Foundation of Guangdong Province (Grant No. 2017A030310644) for the analysis and interpretation of the data China Postdoctoral Science Foundation funded project (2018 T110911) for the writing the manuscript and National Key Clinical Discipline for the design of the study behind writing the manuscript. 


\section{Availability of data and materials}

All data generated and/or analyzed during this study are available from the corresponding author upon reasonable request.

\section{Ethics approval and consent to participate}

The study was approved by the ethics committee of Sun Yat-Sen University Cancer Center (No. GZR2011-10). All subjects were aware of the study protocol and gave written informed consent.

\section{Consent for publication}

Not applicable.

\section{Competing interests}

The authors declare that they have no competing interests.

\section{Author details}

${ }^{1}$ Department of Colorectal Surgery, The Sixth Affiliated Hospital, Sun Yat-sen University, Guangzhou, Guangdong, People's Republic of China. ${ }^{2}$ Guangdong Provincial Key Laboratory of Colorectal and Pelvic Floor Diseases, the Sixth Affiliated Hospital, Sun Yat-sen University, Guangzhou, Guangdong, People's Republic of China. ${ }^{3}$ Department of Radiation Oncology, The Sixth Affiliated Hospital, Sun Yat-sen University, Guangzhou 510655, People's Republic of China. ${ }^{4}$ Department of Clinical Laboratory, Sun Yat-sen University Cancer Center, Guangzhou 510060, People's Republic of China. ${ }^{5}$ State Key Laboratory of Oncology in South China, Guangzhou 510060, People's Republic of China. ${ }^{6}$ Collaborative Innovation Center for Cancer Medicine, Guangzhou 510060, People's Republic of China.

Received: 8 May 2018 Accepted: 10 July 2019

Published online: 07 October 2019

\section{References}

1. Torre LA, Bray F, Siegel RL, et al. Global cancer statistics, 2012. CA Cancer J Clin. 2015;65(2):87-108

2. van de Velde CJ, Boelens PG, Borras JM, et al. EURECCA colorectal: multidisciplinary management: European consensus conference colon \& rectum. Eur J Cancer. 2014:50(1):1.

3. Duffy MJ, van Dalen A, Haglund C, et al. Clinical utility of biochemical markers in colorectal cancer: European group on tumour markers (EGTM) guidelines. Eur J Cancer. 2003;39(6):718-27.

4. Liu D. Gene signatures of estrogen and progesterone receptor pathways predict the prognosis of colorectal cancer. FEBS J. 2016;283(16):3115-33.

5. Rudolph A, Toth C, Hoffmeister M, et al. Expression of oestrogen receptor beta and prognosis of colorectal cancer. Br J Cancer. 2012;107(5):831-9.

6. Caiazza F, Ryan EJ, Doherty G, Winter DC, Sheahan K. Estrogen receptors and their implications in colorectal carcinogenesis. Front Oncol. 2015:5:19.

7. Nussler NC, Reinbacher K, Shanny N, et al. Sex-specific differences in the expression levels of estrogen receptor subtypes in colorectal cancer. Gend Med. 2008;5(3):209-17.

8. Kaklamanos IG, OF B, Franceschi D, et al. Expression of receptors for estrogen and progesterone in malignant colonic mucosa as a prognostic factor for patient survival. J Surg Oncol. 1999;72(4):225-9.

9. DeCosse JJ, Ngoi SS, Jacobson JS, Cennerazzo WJ. Gender and colorectal cancer. Eur J Cancer Prev. 1993;2(2):105-15.

10. Levi F, La Vecchia C, Randimbison L, Te VC, Franceschi S. Patterns of large bowel cancer by subsite, age, sex and marital status. TUMORI. 1991;77(3):246-51.

11. Lin KJ, Cheung WY, Lai JY, Giovannucci EL. The effect of estrogen vs. combined estrogen-progestogen therapy on the risk of colorectal cancer. Int J Cancer. 2012:130(2):419-30.

12. Hoffmeister M, Raum E, Krtschil A, Chang-Claude J, Brenner H. No evidence for variation in colorectal cancer risk associated with different types of postmenopausal hormone therapy. Clin Pharmacol Ther. 2009;86(4):416-24.

13. Chen J, Iverson D. Estrogen in obesity-associated colon cancer: friend or foe? Protecting postmenopausal women but promoting late-stage colon cancer. Cancer Causes Control. 2012;23(11):1767-73.

14. $\mathrm{Xu} C Y$, Guo $\mathrm{J}$, Jiang $Z \mathrm{~N}$, et al. Prognostic role of estrogen receptor alpha and estrogen receptor beta in gastric cancer. Ann Surg Oncol. 2010;17(9): 2503-9.

15. Kawai $H$, Ishii A, Washiya $K$, et al. Estrogen receptor alpha and beta are prognostic factors in non-small cell lung cancer. Clin Cancer Res. 2005: 11(14):5084-9.
16. Villa E, Colantoni A, Grottola A, et al. Variant estrogen receptors and their role in liver disease. Mol Cell Endocrinol. 2002;193(1-2):65-9.

17. Park SH, Cheung LW, Wong AS, Leung PC. Estrogen regulates snail and slug in the down-regulation of E-cadherin and induces metastatic potential of ovarian cancer cells through estrogen receptor alpha. Mol Endocrinol. 2008; 22(9):2085-98.

18. Fang YJ, Lu ZH, Wang F, et al. Prognostic impact of ERbeta and MMP7 expression on overall survival in colon cancer. Tumour Biol. 2010;31(6):651-8.

19. Fang YJ, Zhang L, Wu XJ, et al. Impact of ERbeta and CD44 expression on the prognosis of patients with stage II colon cancer. Tumour Biol. 2012; 33(6):1907-14

20. Armstrong CM, Billimek AR, Allred KF, et al. A novel shift in estrogen receptor expression occurs as estradiol suppresses inflammation-associated colon tumor formation. Endocr Relat Cancer. 2013;20(4):515-25.

21. Dong J, Jiang SW, Niu Y, et al. Expression of estrogen receptor alpha and beta in esophageal squamous cell carcinoma. Oncol Rep. 2013;30(6):2771-6.

22. Heijmans J, Muncan $V$, Jacobs RJ, et al. Intestinal tumorigenesis is not affected by progesterone signaling in rodent models. PLoS One. 2011;6(7):e22620.

\section{Publisher's Note}

Springer Nature remains neutral with regard to jurisdictional claims in published maps and institutional affiliations.
Ready to submit your research? Choose BMC and benefit from:

- fast, convenient online submission

- thorough peer review by experienced researchers in your field

- rapid publication on acceptance

- support for research data, including large and complex data types

- gold Open Access which fosters wider collaboration and increased citations

- maximum visibility for your research: over $100 \mathrm{M}$ website views per year

At $\mathrm{BMC}$, research is always in progress.

Learn more biomedcentral.com/submissions 